\title{
UNRRA and Support for Science
}

\section{J. Frydryšková}

The Second World War was the most devastating war in history. Millions of people died, countless cities were destroyed and economic recovery was one of the most important problems dealt with in past-war conferences. The US needed an economically stable Europe, and for this reason they started preparing a recovery program before the war came to an end. One of the most important programs was UNRRA. UNRRA consisted of two parts - relief and rehabilitation. An important part of rehabilitation was the Fellowships Program, which was the first international scholarship program after the Second World War. This program provided scholarships for specialists from every country that received help from UNRRA. These specialists returned to their own country after their residency and helped with the recovery. This was the main reason for the Fellowships program.

Keywords: Post-war recovery, UNRRA, Fellowship Program.

\section{UNRRA}

The abbreviation UNRRA stands for the United Nations Relief and Rehabilitation Administration. This organization was established on the proposal of American President Franklin Delano Roosevelt. On November 9, 1943 deputies from 44 countries, which were fighting against a common enemy Nazi Germany and its allies-gathered in the White House in Washington. There they signed an agreement to establish UNRRA (for Czechoslovakia the document was signed by Jan Masaryk, foreign minister in the Czechoslovak government-in-exile). The fundamental idea was to establish mutual economic cooperation in the post-war period, and to assist in rehabilitating and renewing war-devastated countries. Participation in reconstruction was not a part of UNRRA activities, and there was no long-term cooperation in economic programs and agreements. The aim of this cooperation was to use world resources to help the countries immediately affected by the war, countries which did not have their own resources to recover from the consequences of World War II. In the period of urgent assistance (so-called relief), UNRRA primarily supplied food, clothing, and medicine. The program, contributed to some supplementary health and socio-political services, and cooperated repatriating refugees dispersed all round the world.

In the period of renewal (so-called rehabilitation), UNRRA supplied the liberated countries with goods needed to rehabilitate their production and transport networks. For

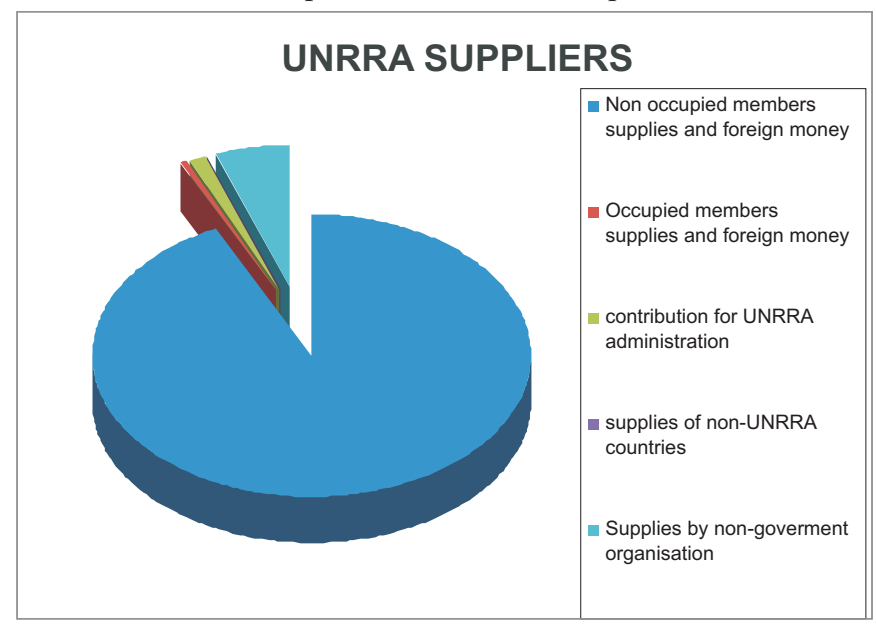

Fig. 1: Woodbridge, G., The History of UNRRA, I. Volume, p. 105

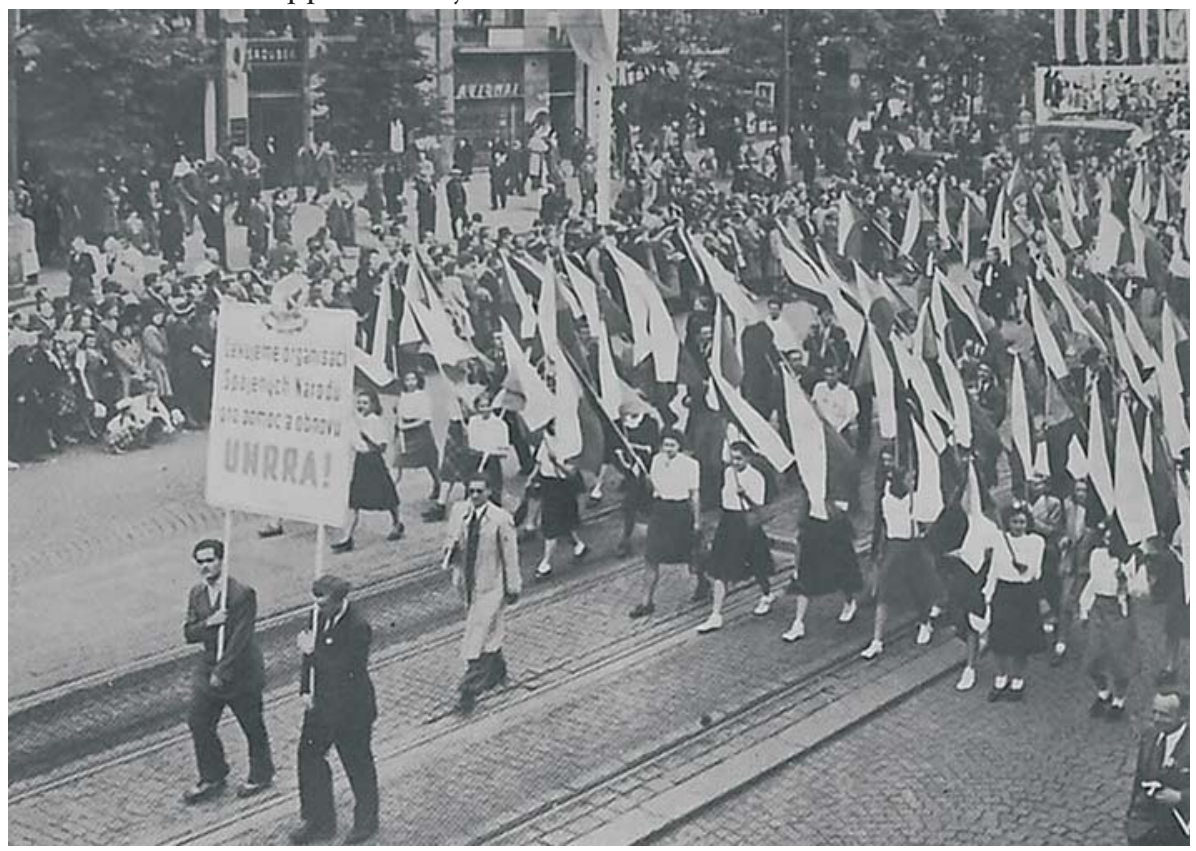

Fig. 2: UNRRA in Czechoslovakia, p. 177 
example, seeds, fertilizers, raw materials, fishing gear, industrial machinery and parts were supplied. UNRRA also contributed to the renewal of important installations such as waterworks, electric power plants and gasworks, restoration of the infrastructure and procurement of materials for renewing educational institutions.

\section{Fellowship program}

In addition to these joint activities, UNRRA worked on developing advanced science and engineering in the war-afflicted countries. The leaders of this organization clearly realized that countries occupied for a long time by the enemy face a shortage of well-qualified people. Originally, UNRRA sent all sorts of experts to the war-devastated countries. They trained local specialists, and thus accelerated the rehabilitation process in the devastated countries. The experts also brought the local scientific communities into contact with the latest technical, scientific and medical discoveries. In spite of this creditable activity, the measures were considered temporary because the seven years of imposed separation of scholars and scientific workers from other scientific and specialist communities could not be made good by short-term specialized discussions.

The council of UNRRA decided to run a scholarship program that would enable engineers, experts, doctors and scientific workers to acquaint themselves with the latest achievements in their spheres. Thus, the UNRRA Fellowship Program was established. The UNRRA relief recipient countries were given an opportunity to send specialists to the USA, Canada and Great Britain to learn about the latest advances made by their colleagues and to implement the experience that they acquired in their home countries. Scholarship holders, who had been proposed by the government itself, were appointed as UNRRA experts when they returned home.

A total of 155 six-month and nine-month scholarships were provided. Czechoslovakia obtained 21 scholarship places for its candidates. Eighteen were sent to the USA and Canada, and only three went to France and Great Britain.

Each grant holder was given some training and other introductory courses. Then he/she was sent to a department, institution or factory where he/she studied and specialize in a specific topic. Many of the scholars took specialized courses at a university. All were required to write a concluding report, which had the following structure: 1) program studies, 2) ac-

Table 1: Fields of study of UNRRA Fellowships holders

\begin{tabular}{|l|c|c|}
\hline Field & Total & No. in U.S.A. \\
\hline Health & 25 & 16 \\
\hline Penicillin & 5 & 5 \\
\hline Welfare & 20 & 18 \\
\hline Public services & 6 & 5 \\
\hline Agricultural rehabilitation & 32 & 27 \\
\hline Industrial rehabilitation & 67 & 55 \\
\hline TOTAL & 155 & 126 \\
\hline
\end{tabular}

quired technical and scientific information, 3) proposals for aid and renewal of his/her scope in his/her homeland; 4) list of places he/she studied at, 5) list of special literature and facilities. The UNRRA council sent this final report to the government of the scholarship holder.

The candidates who successfully passed the courses received a letter from UNRRA (a Certificate of Merit), signed personally by the Director-General.

In addition, UNRRA prepared a plan to improve in-hospital care. In six European countries, including Czechoslovakia, about 100 nurses were chosen to go to the United State, where they were trained in the latest methods. All expenses for a three-month stay were covered by UNRRA.

\section{Conclusion}

It should be pointed out that this was the first large-scale grant program of its kind after World War II. Despite all the difficulties, it met people's expectations. UNRRA Director-General L. W. Rookse provided proof of this. On his European tour, he proclaimed that: "The returning grant holders teach, conduct studies, reorganize and are very valued persons in the renewal process of their own countries. In many European countries the recovery often depends on the technical guidance and efficiency of that handful of educated men and women."

The significance of these activities was tremendous; the scholarship holders from the recipient countries were able to enter into personal relations, exchange opinions and experience, and also to become familiar with technical and scientific progress in countries away from the battlefields. The experience and results of this first scholarship program established a model for international organizations, e.g., UNESCO, which was developing similar concepts of scholarship programs at that time.

\section{Acknowledgments}

The research described in this paper was supervised by Prof. PhDr. Ivan Jakubec, CSc., Institute for Economic and Social History, Philosophical Faculty of Charles University in Prague.

\section{References}

[1] Dowd, A. W.: Exporting Civil Society. Contributors. In: World, Vol. 18 (2003), number 7, p. 255-265.

[2] UNRRA in Czechoslovakia, Prague, 1971.

[3] Woodbridge. G.: UNRRA - The History of the United Nations Relief und Rehabilitation Administration I., II., III. Part, Columbia University, 1950.

[4] FUND - UNRRA, National Archives, Prague.

Jana Frydryšková

e-mail: j.frydryskova@seznam.cz

The Institute for Economic and Social History

Philosophical Faculty of Charles University

Celetna 20

11642 Prague 1, Czech Republic 